\title{
La razón de ser de los conglomerantes
}

I. M. FERNANDEZ PARIS

Prof. Numerario de Física y Perito Químico Jefe de la Sección de Química de INTEMAC, s. A.

La palabra cemento sirve para designar cualquier sustancia con capacidad adherente, mientras que el término conglomerante se aplica a la acción de aglutinar en un todo partículas que anteriormente estaban sueltas o independientes.

Según su capacidad o no de endurecer bajo agua, los conglomerantes se clasifican en hidráulicos y no hidráulicos. Se denominan hidráulicos a aquéllos que tienen la citada facultad.

Entre todos los conglomerantes hidráulicos, han adquirido en la construcción una carta de naturaleza inusitada durante los últimos tiempos los denominados cementos portland.

Quiero hacer constar que trato de exponer simplemente aquellos conceptos químicos que, a mi modo de ver y de acuerdo con mi experiencia, constituyen la razón de ser que nos permita apreciar sus cualidades y propiedades.

\section{CARACTERISTICA HIDRAULICA}

La noción de hidraulicidad de un conglomerante surgió durante el proceso de fabricación de las cales y precisamente al calcinar caliząs pobres con un elevado residuo arcilloso. Los investigadores de aquella época, siglo XIX, tales como Vicat y Smeaton, supusieron que entre la arcilla y la cal se originaban compuestos de naturaleza hidráulica.

Las reacciones que tienen lugar al calcinar una caliza pura son:

$$
\begin{array}{ll}
\mathrm{CO}_{3} \mathrm{Ca}+1.000^{\circ} \mathrm{C} \rightarrow & \mathrm{CaO}+\mathrm{CO}_{2} \uparrow \\
\text { caliza } & \text { cal viva }
\end{array}
$$

Las reacciones que tienen lugar al calcinar una caliza arcillosa, también denominada pobre, son:

$$
\begin{array}{ll}
\mathrm{CO}_{3} \mathrm{Ca}-\text { arcilla }+1.000^{\circ} \mathrm{C} \rightarrow & \operatorname{arcilla}-\mathrm{CaO}+\mathrm{CO}_{2} \uparrow \\
\text { caliza pobre } & \text { cal hidráulica }
\end{array}
$$

Por tanto, la fabricación de las cales hidráulicas fue la idea fundamental del cemento portland: es decir, la formación de silicatos cálcicos de carácter hidráulico. 
Quiero subrayar que el carácter hidráulico consiste en la capacidad de un conglomerante para fraguar y endurecer bajo agua, o sea, sumergido en la misma. Hay quien entiende por hidráulico la simple acción de amasar con agua. Esta propiedad confiere a los conglomerantes cualidades fundamentales para la construcción de obras hidráulicas y marítimas.

\section{COMPOSICION DEL CEMENTO PORTLAND}

Al estudiar la formación de los componentes mineralógicos quei integran el clínker del cementa portland, se comprobó y hoy día, se ve en su análisis químico que se compone principalmente de $\mathrm{SiO}_{2}, \mathrm{Al}_{2} \mathrm{O}_{3}, \mathrm{Fe}_{2} \mathrm{O}_{3}$ y $\mathrm{CaO}$; el resto de los componentes, tales como el $\mathrm{MgO}$ y los álcalis, se consideran secundarios y. no implican caracteres fundamentales.

Con poco que se recuerde de Química, se puede comprobar que de los cuatro componentes principales el único que tiene carácter marcadamente básico es la cal, $\mathrm{CaO}$. La sílice, $\mathrm{SiO}_{2}$, tiene un carácter marcadamente ácido y la alúmina, $\mathrm{Al}_{2} \mathrm{O}_{3}$, y el hierro, $\mathrm{Fe}_{2} \mathrm{O}_{3}$, carácter anfótero.

Por consiguiente, desde el punto de vista químico, se han de formar forzosamente las correspondientes sales cálcicas de los tres elementos ácidos citados, es decir, silicatos cálcicos, aluminatos cálcicos y ferritos cálcicos.

La capacidad que cada uno de estos tres elementos ácidos tienen para reaccionar con una mayor o menor cantidad de cal, depende, entre otras variables, de las condiciones en que se verifiquen las reacciones, tales como estado, temperatura y presión.

En condiciones ambientales el $\mathrm{SiO}_{2}$ no reacciona con la cal, $\mathrm{CaO}$, pero, en determinadas zonas terrestres que gozan de características hidrotérmicas, se ha detectado la presencia de un silicato bicálcico, $\mathrm{SC}_{2}$, denominado mineralógicamente Brediggita. Si se quiere aumentar el grado de saturación en cal, o sea, formar $\mathrm{SC}_{3}$, es preciso aumentar la temperatura hasta $1.400^{\circ} \mathrm{C}$.

De forma análoga se comporta el $\mathrm{Al}_{2} \mathrm{O}_{3}$ pudiendo originarse un aluminato monobásico, $\mathrm{AC}$, a temperaturas hidrotermales y un aluminato tricálcico, $\mathrm{AC}_{3}$, es decir, más saturado, a temperaturas de 700 y $800^{\circ} \mathrm{C}$.

El $\mathrm{Fe}_{2} \mathrm{O}_{3}$, en las condiciones que tiene lugar la formación del clínker de cemento, se combina con los aluminatos para formar $\mathrm{FAC}_{4}$ de composición variable, por tratarse de una disolución sólida.

Por consiguiente, los principales componentes mineralógicos de clínker de cemento portland son:

SILICATO TRICALCICO: $\quad \mathrm{SiO}_{2} \cdot 3 \mathrm{CaO} \quad\left(\mathrm{SC}_{3}\right) \quad$ Alita

SILICATO BICALCICO: $\quad \mathrm{SiO}_{2} \cdot 2 \mathrm{CaO} \quad\left(\mathrm{SC}_{2}\right) \quad$ Belita

ALUMINATO TRICALCICO: $\quad \mathrm{Al}_{2} \mathrm{O}_{3} .3 \mathrm{CaO} \quad\left(\mathrm{AC}_{3}\right)$ Celita

FERRITO ALUMINATO TETRACALCICO: $\mathrm{Fe}_{2} \mathrm{O}_{3} \cdot \mathrm{Al}_{2} \mathrm{O}_{3} \cdot 4 \mathrm{CaO} \quad\left(\mathrm{FAC}_{4}\right)$

\section{Formación de los componentes en el horno rotatorio}

Las materias primas para la obtención del c'ínker son las calizas y las arcillas, que mezcladas en proporciones adecuadas constituyen el crudo de cemento. 
La piedra caliza es una roca sedimentaria formada por carbonato cálcico, $\mathrm{CO}_{3} \mathrm{Ca}, \mathrm{y}$ una cantidad muy variable de impurezas arcillosas. Es la materia prima que aporta el elemento básico, $\mathrm{CaO}$.

Las arcillas proceden de la descomposición de los silicatos, generalmente feldespatos y areniscas, y pueden considerarse como unos silicatos de aluminio y hierro. Las arcillas suelen contener como impurezas cantidades variables de caliza y magnesia. Constituye la materia prima que aporta los elementos ácidos: $\mathrm{SiO}_{2}, \mathrm{Al}_{2} \mathrm{O}_{3}, \mathrm{Fe}_{2} \mathrm{O}_{3}$.

Las calizas y las arcillas, conforme puede deducirse, no son especies puras y sus composiciones químicas varían en un amplio entorno de acuerdo con sus impurezas.

Antes de $1.000^{\circ} \mathrm{C}$ la caliza y la arcilla pierden el $\mathrm{CO}_{2}$ y el agua de constitución respectivamente:

$$
\begin{aligned}
& \mathrm{CO}_{3} \mathrm{Ca}+\text { calor } \rightarrow \mathrm{CaO}+\mathrm{CO}_{2} \\
& \text { Arcilla }+ \text { calor } \rightarrow \text { Arcilla activada }+\mathrm{H}_{2} \mathrm{O}
\end{aligned}
$$

quedando la cal, $\mathrm{CaO}$, de carácter básico, en disposición de reaccionar con los componentes ácidos de la arcilla, que a su vez se encuentran activados.

A $1.200^{\circ} \mathrm{C}$ el $\mathrm{CaO}$ se combina con el $\mathrm{Al}_{2} \mathrm{O}_{3}$ y $\mathrm{Fe}_{2} \mathrm{O}_{3}$, para originar el aluminato tricálcico y el ferrito aluminato tetracálcico.

$$
\begin{gathered}
\mathrm{Al}_{2} \mathrm{O}_{3}+3 \mathrm{CaO} \rightarrow \mathrm{Al}_{2} \mathrm{O}_{3} \cdot 3 \mathrm{CaO} \quad\left(\mathrm{AC}_{3}\right) \\
\mathrm{Fe}_{2} \mathrm{O}_{3}+\mathrm{Al}_{2} \mathrm{O}_{3}+4 \mathrm{CaO} \rightarrow \mathrm{Fe}_{2} \mathrm{O}_{3} \cdot \mathrm{Al}_{2} \mathrm{O}_{3} \cdot 4 \mathrm{CaO}\left(\mathrm{FAC}_{4}\right)
\end{gathered}
$$

ambos compuestos forman una masa pastosa de consistencia semilíquida, denominada lecho fluido, en el cual flotan los dos componentes restantes, $\mathrm{SiO}_{2}$ y $\mathrm{CaO}$.

La formación de este lecho fluido es indispensable para que se verifiquen las reacciones posteriores entre la sílice, $\mathrm{SiO}_{2}$, y ia cal, CaO. Esta acción constituye la base primordial y el trascendental descubrimiento de Johnson de clinkerizar los crudos de cemento. Por ello, al $\mathrm{Al}_{2} \mathrm{O}_{3}$ y $\mathrm{Fe}_{2} \mathrm{O}_{3}$ se les denomina fundentes.

A $1.200^{\circ}-1.300^{\circ} \mathrm{C}$ reacciona la cal con la sílice para dar silicato bicálcico:

$$
\mathrm{SiO}_{2}+2 \mathrm{CaO} \rightarrow \mathrm{SiO}_{2} \cdot 2 \mathrm{CaO} \quad\left(\mathrm{SC}_{2}\right)
$$

compuesto que ya tiene carácter hidráulico. No obstante, si los conglomerantes tuvieran únicamente este tipo de silicato, adquirirían resistencias solamente a largo plazo.

A $1.400^{\circ}-1.450^{\circ} \mathrm{C}$ una parte del silicato bicálcico formado reacciona con la cal restante para formar silicato tricálcico:

$$
\mathrm{SC}_{2}+\mathrm{CaO} \rightarrow \mathrm{SC}_{3}
$$

componente hidráulico por excelencia, al cual se deben las elevadas resistencias iniciales de los cementos.

La masa que reacciona dentro del horno a partir de la formación del lecho fluido, de textura viscosa, tiende a formar esferas o bolitas y, de esta forma, sale por la boca del horno, constituyendo el clínker de cemento portland. 


\section{INESTABILIDAD DE LOS DISTINTOS COMPUESTOS DEL CLINKER}

Los componentes del clinker, $\mathrm{SC}_{3}, \mathrm{SC}_{2}, A C_{3}, F A C_{4}$, se han podido formar, como hemos visto anteriormente, gracias al enorme aporte energético que el horno ha transmitido a la masa del crudo.

Es preciso tomar conciencia clara de que estos compuestos, por encerrar en su disposición cristalina una gran cantidad de energía, son altamente inestables, es decir, si una vez formados se dejaran a su ser, se descompondrían, degradándose, para formar compuestos más estables, de menor contenido energético y distinta estructura cristalina.

Si se quiere conservar estos compuestos, se hace preciso "coagular" el sistema químico formado en el horno, o sea, someter la masa a un proceso rápido de templado, análogo al que sufren los aceros, con el fin de estabilizar la situación cristalográfica y química de los componentes. En una palabra, hay que someter la masa del clinker a un proceso rápido de enfriamiento o a un enérgico templado.

Es obvio destacar que el poder conglomerante y por tanto las resistencias, dependen precisamente del carácter inestable de los componentes y que la energía acumulada en forma química es la que mediante la hidratación va a transformarse en energía mecánica y calor durante su hidratación.

\section{Influencia del enfriamiento en los conglomerantes}

El clínker, cuando sale del horno, debe caer en un enfriador con el fin de congelar, como he indicado, el estado en que se encuentran los distintos componentes mineralógicos.

Si estos compuestos, que prácticamente se hallan a una temperatura de $1.450^{\circ} \mathrm{C}$, se dejaran enfriar lentamente hasta temperatura ambiente, los distintos componentes mineralógicos se degradarían:

1. ${ }^{\circ}$ El silicato tricálcico se desdobla en silicato bicálcico y óxido de calcio (cal libre)

$$
\mathrm{SC}_{3} \rightarrow \mathrm{SC}_{2}+\mathrm{C}
$$

lo cual supone una pérdida de cualidades energéticas y por tanto resistentes, independientemente de que la presencia de óxido de cal, denominado cal libre, es perjudicial, ya que un contenido excesivo da origen a posteriores reacciones de expansión.

2. $\quad$ El silicato bicálcico, al enfriarse lentamente, adopta una estructura cristalina particular, denominada "gamma", que suele ir acompañada de fenómenos de autopulverización del clínker.

3. Los aluminatos y ferrito aluminatos de calcio, que se hallan en forma vítrea, al descender la temperatura paulatinamente, tienen tiempo de cristalizar, motivando trastornos en el fraguado y, lo que es más grave, fenómenos de expansión en las pastas de los cementos.

Una vez que el clínker sale del enfriador se somete a un proceso de molturación, conjuntamente con la piedra de yeso que regula su fraguado, con el fin de que durante su utilización, posterior se ponga una gran superficie de su masa en contacto con el agua de amasado y manifieste sus cualidades conglomerantes. El proceso de molturación se lleva hasta obtener una finura de unos $3.800 \mathrm{~cm}^{2} / \mathrm{g}$ Blaine. 


\section{DISTINTOS TIPOS DE CLINKER PORTLAND}

Para que se produzca la formación del clínker se precisan dos condiciones:

1. Un "lecho fluido" de aproximadamente un $20 \%$.

$2{ }^{\circ} \quad$ Un grado de saturación que, al menos, permita la formación de un $20 \%$ de $\mathrm{SC}_{3}$.

Puesto que el "lecho fluido" está integrado por los aluminatos cálcicos y ferrito aluminatos cálcicos, pueden variar sus contenidos dentro de un total de $20 \%$ y de este modo obtener los lechos fluidos extremos:

\begin{tabular}{|c|c|c|c|}
\hline & $\begin{array}{c}\text { Alto en } \\
\text { Aluminatos }\end{array}$ & $\begin{array}{l}\text { Bajo en } \\
\text { Aluminatos }\end{array}$ & Normal \\
\hline $\mathrm{AC}_{3} \%=$ & $18 \%$ & $2 \%$ & $11 \%$ \\
\hline $\mathrm{FAC}_{4} \%=$ & $2 \%$ & $18 \%$ & $9 \%$ \\
\hline
\end{tabular}

La primera proporción corresponde a clínkeres portland de alto contenido de aluminatos y la segunda a bajos en aluminatos, también denominados (PAS) ó (P-Y) en los Pliegos PCCH-64 y RC-75, respectivamente.

Variando el grado de saturación en cal, se obtienen diferentes gamas de silicatos cálcicos:

$$
\begin{aligned}
& \mathrm{SC}_{3}=65 \% \quad \mathrm{y} \quad \mathrm{SC}_{2}=\begin{array}{llllllllllll}
10 & \% & \ldots & \ldots & \ldots & \ldots & \ldots & \ldots & \ldots & \ldots & \ldots & \text { Clínker alítico }
\end{array} \\
& \mathrm{SC}_{3}=20 \% \quad y \quad \mathrm{SC}_{2}=\begin{array}{lllllllllllll}
55 & \% & \ldots & \ldots & \ldots & \ldots & \ldots & \ldots & \ldots & \ldots & \ldots & \text { Clínker belítico }
\end{array}
\end{aligned}
$$

Combinando adecuadamente las proporciones de fundentes y el grado de saturación en cal, se pueden obtener los siguientes tipos de clínker:

Rico en aluminatos y alítico

Rico en aluminatos y belítico

Normal

Tipo P-Y y alítico

Tipo P-Y y belítico

Si se tiene en consideración que los componentes condicionan las siguientes características:

$\mathrm{SC}_{3} \ldots \ldots .$. resistencias iniciales; elevado calor;

$\mathrm{SC}_{2}$........ resistencias finales; bajo calor;

$\mathrm{AC}_{3} \ldots . . . .$. resistencias tempranas; elevadísimo calor,

se pusde conseguir una gama muy extensa de cementos portland.

\section{EL PAPEL DEL YESO COMO REGULADOR DEL FRAGUADO}

Durante la molienda del clínker se adiciona, aproximadamente, un $5 \%$ en peso de piedra de yeso, es decir, sulfato cálcico dihidrato, $\mathrm{SO}_{4} \mathrm{Ca} .2 \mathrm{H}_{2} \mathrm{O}$, con el fin de regular su fraguado. 
Si sz amasara únicamente el clínker molido con agua, éste endurecería casi inmediatamente, debido a la pronta disolución y formación de los aluminatos cálcicos hidratados que aceleran la hidrólisis del silicato tricálcico.

El endurecimiento del cemento es el resultado del proceso de hidrólisis de los silicatos cálcicos y la subsiguiente precipitación del hidróxido de cal que actúa como agente aglutinante. La formación de una masa voluminosa, denominada entumecimiento, es el resultado de amasar el cemento con agua o con otra disolución que actúe disolviendo los silicatos cálcicos y precipitando el hidróxido de cal.

Como norma general cualquier sal de calcio en disolución acelera el endurecimiento. La acción se deba a una disminución del $\mathrm{pH}$ que causa una rápida disolución de los silicatos cálcicos y, finalmente, la concentración de ion calcio aumenta, originando una rápida formación del hidróxido.

Según la teoría expuesta, el yeso, por tratarse de una sal cálcica debería acelerar el proceso de endurecimiento y fraguado del clínker, sin embargo, ejerce una acción reguladora que trataré de explicar.

El yeso actúa debido a la formación de compuestos complejos, denominados sulfoaluminatos cálcicos, cuando reacciona con los aluminatos cálcicos del clínker:

$$
\begin{aligned}
& 3 \mathrm{SO}_{4} \mathrm{Ca} .2 \mathrm{H}_{2} \mathrm{O}+\mathrm{AC}_{3}+30 \mathrm{H}_{2} \mathrm{O} \rightarrow \mathrm{AC}_{3} \cdot 3 \mathrm{SO}_{4} \mathrm{Ca} .32 \mathrm{H}_{2} \mathrm{O} \\
& \text { yeso Aluminato Sulfoaluminato cálcico } \\
& \text { cálcico }
\end{aligned}
$$

Los sulfoaluminatos formados precipitan en forma de finas agujas que se depositan sobre la superficie de los restantes aluminatos y silicatos cálcicos retardando su hidrólisis y, por consiguiente, el endurecimiento.

Muchas veces han hecho la pregunta de la misión que cumple la adición de piedra de yeso al cemento que prácticamente carece de aluminatos de' calcio, (P-Y) ó (PAS) si su acción se centra en éstos. La respuesta es muy simple. Si amasamos un clínker tipo PAS tardaría mucho en fraguar y endurecer porque los silicatos tienen difícil hidrólisis. El yeso actúa simplemente como una sal cálcica que acelera el fraguado.

Por consiguiente, el yeso regula el fraguado de los cementos portland normales y de alto contenido de aluminatos y acelera el fraguado de los cementos exentos de aluminatos de calcio.

\section{FORMACION DE LOS COMPUESTOS HIDRATADOS DEL CEMENTO}

\section{Hidratación de los silicatos}

El $\mathrm{SC}_{3}$ y el $\mathrm{SC}_{2}$ constituyen aproximadamen'e el $75 \%$ en pesc del cemento portland. La hidratación de ambos produce silicatos cálcicos hidratados muy semejantes e hidróxido cálcico.

Al silicato cálcico hidratado, por su analogía con el mineral natural denominado tobermorita, así como por sus características de gel, se le ha denominado "gel de tobermorita". 
Cuando se mezcla silicato tricálcico, $\mathrm{SC}_{3}$, con una cantidad de agua ( 0,7 veces su peso), proporción bastante parecida a las pastas industriales, el examen de la pasta endurecida indica que la reacción ha sido:

$$
\begin{aligned}
2 \mathrm{SC}_{3}+6 \mathrm{H}_{2} \mathrm{O} \rightarrow \underset{3}{\text { gel de }} \rightarrow & \mathrm{C}_{2} \mathrm{H}_{3}+3 \mathrm{Ca}(\mathrm{OH})_{2} \\
\text { tobermorita } & \text { portlandita }
\end{aligned}
$$

El silicato bicálcico, $\mathrm{SC}_{2}$, tiene una velocidad de reacción con el agua mucho más lenta, posiblemente porque su estructura está bastante más empaquetada que la del $\mathrm{SC}_{3}$ que, al parecer, tiene huecos, lo que facilita su ataque; en este caso la reacción que tiene lugar es:

$$
\begin{aligned}
& 2 \mathrm{SC}_{2}+4 \mathrm{H}_{2} \mathrm{O} \rightarrow \mathrm{C}_{3,3} \mathrm{~S}_{2} \mathrm{H}_{3,3}+0,7 \mathrm{Ca}(\mathrm{OH})_{2} \\
& \text { gel de portlandita } \\
& \text { tobermorita }
\end{aligned}
$$

Las composiciones químicas del "gel de tobermorita" en las expresiones anteriores son diferentes. Por ejemplo, la relación molar $\mathrm{CaO} / \mathrm{SiO}_{2}$ es de 1,5 para la primera y de 1,65 para la segunda. A pesar de todo, ambos geles son muy semejantes y sus diagramas de DRX son idénticos; el examen al microscopio elecirónico revela la misma morfología.

A la vez que se origina el "gel de tobermorita" se forma $\mathrm{Ca}(\mathrm{OH})_{2}$ hidróxido cálcico, denominado portlandita, en forma de láminas hexagonales.

\section{Hidratación de los aluminatos}

Contrariamente a lo que sucede con los silicatos cálcicos, en cuyos granos penetra el agua y se efectúa una disolución parcial, los aluminatos de calcio se disuelven en el agua, sin duda porque la alúmina es mucho menos polimerizable que la sílice.

La disolución rápida de los aluminatos en agua hace que la superficie de los granos primitivos desaparezca durante el proceso de la hidratación, creando una disolución de discontinuidad entre los granos hidratados.

Por otra parte hay que tener en consideración que la hidratación de los cementos se verifica no en agua pura, sino en una disolución saturada de hidróxido cálcico y en presencia de yeso, sustancia que conforme he indicado, se añade al clínker para regular su fraguado.

La presencia de iones sulfato y del hidróxido de cal disueltos en el agua de hidratación complican la mecánica de formación de los aluminatos hidratados, pudiendo interpretarse que en las condiciones normales de amasado y curado de morteros y hormigones, la hidratación de los aluminatos de calcio se verifica en tres períodos característicos:

1. ${ }^{\circ}$ El aluminato se combina con los sulfatos en medio básico del $\mathrm{Ca}(\mathrm{OH})_{2}$ formando ettringita, alrededor de la superficie de los granos.

2. Los aluminatos restantes que no han reaccionado con los sulfatos se hidratan en un medio básico de $\mathrm{Ca}(\mathrm{OH})_{2}$

$$
\mathrm{AC}_{3}+\mathrm{Ca}(\mathrm{OH})_{2}+12 \mathrm{H}_{2} \mathrm{O} \rightarrow \underset{\text { hexagonal }}{\mathrm{C}_{4} \mathrm{AH}_{13}}
$$


3. El aiuminato cálcico hidratado reacciona con la ettringita para dar lugar a un monosulfoaluminato cálcico. Esta última reacción se verifica con una ligera disminución de volumen y desprendimiento de humedad.

Por consiguiente, los aluminatos de calcio dan lugar a tres compuestos presentes en las pastas hidratadas:

- Aluminato cálcico hexagonal.

- Ettringita.

- Monosulfoaluminato cálcico.

La reacción entre el agua de yeso y los ferri :o aluminatos de calcio es lentísima y, únicamente, después de un tiempo muy largo (meses), se obtiene una fase semihidratada.

\section{LA PASTA DE CEMENTO HIDRATADO}

Las reacciones anteriores de hidratación dan lugar a la pasta de cemento endurecida.

La pasta de cemento endurecida es una estructura rígida. Conviene destacar el término estructura que, en este caso, es más importante que el de compuesto químico, puesto que una misma sustancia química puede dar lugar a distintas estructuras.

Los productos de las reacciones de hidratación se presentan como masas densas de porosidad característica, que reciben la denominación de "gel de cemento" por su homología con los productos coloidales. La fracción de pasta que no está ocupada por el "gel de cemento" se denomina "espacio capilar".

Una vez establecidos dichos términos puede considerarse que la pasta de cemento es un material multifase, compuesto por partículas de cemento sin hidratar, embebidas en una matriz continua de "gel de cemento", atravesada por poros de gel y poros capilares ocupados por agua.

En el interior del "gel de cemento" se encuミntran los denominados "poros del gel", de tamaño inferior a los "poros capilares".

Para estudiar la pasta de cemento portland ha sido necesario idear un modelo estructural, debido a Powers, concebido sobre la base de que los granos de cemento están rodeados de una masa coherente de "gel de cemento" sin llenar por completo los espacios intergranulares.

El "gel de cemento", según los estudios muy recientes de Czernin, mediante la microscopía electrónica, está formado por láminas arrolladas a modo de tubos en espiral, como si fuesen concéntricos, excepto en las zonas limítrofes, que se adaptan a los contornos. Los ejes de los distintos tubos están orientados al azar, formando un auténtico fieltro. El carácter laminar de la estructura del "gel de cemento" tiene un interés especial; las láminas se corresponden con bastante probabilidad con los "geles de tobermorita" $y$ los poros entre dichas láminas se corresponden con los denominados "poros de gel".

Los diferentes tubos que integran la estructura del "gel de cemento" están soldados entre sí por las placas hexagonales de portlandita, que constituye, aproximadamente, de un 20 a un $30 \%$ en peso del "gel de cemento" seco. 


\section{Etapas de formación de la pasta}

La formación de la pasta comprende tres periodos.

Período latente, desde el comienzo de la mezcla del cemento con el agua hasta la pérdida de plasticidad al cabo de unas 2 horas. Durante los primeros 5 minutos de amasado, las reacciones químicas se producen con una enorme rapidez y a partir de este tiempo el proceso decae. Durante este primer período la masa es un sólido plástico.

Concluido el período latente continúa una segunda etapa, denominada de transición, durante la cual la pasta pierde su plasticidad y pasa por unos gradientes de consistencia, que se denominan arbitrariamente, "principio y fin de fraguado".

El tercer período o de enđurecimiento, la pasta es un sólido rígido.

De este modo se llega a la estructura de la pasta endurecida.

\section{Carácter básico de la pasta enđurecida}

Anteriormente, tanto al hablar de la estructura como de los compuestos hidratados, se ha citado al hidróxido cálcico o portlandita como un componente fundamental de la pasta endurecida. Independientemente del papel ligante con los "geles de tobermorita" cumple una función trascendental, para bien y para mal de los morteros y hormigones, cual es la de comunicar un elevado carácter básico a las disoluciones acuosas en contacto con dicha pasta. Esta fuerte basicidad potencial juega un papel fundamental en:

- La formación de los cementos compuestos,

- Durabilidad de las pastas en morteros y hormigones y

- Corrosión de armaduras.

\section{Los cementos compuestos}

Se denominan así a aquellos conglomerantes que están integrados por clínker de cemento portland $y$ otro componente activo, tal como puzolana y escorias, obteniéndose de este modo los cementos puzolánicos y los de escorias.

Los cementos puzolánicos, en términos generales, contienen un $70 \%$ de clínker, $25 \%$ de puzolana y $5 \%$ de yeso. Como puzolana, en términos de construcción, se conoce toda sustancia que no es capaz de endurecer por si sola, pero que amasada con hidróxido cálcico forma compuestos hidráulicos estables.

Si se tiene en cuenta que el cemento portland, al ser amasado con agua, libera hidróxido cálcico, se podrá sustituir una cierta cantidad de cemento por una sustancia puzolánica y obtener así conglomerantes puzolánicos. La puzolana pone su actividad latente de carácter físico y químico y el clínker la cal que aquélla precisa para endurecer.

Los cementos de escorias contienen un $70 \%$ de escorias, $25 \%$ de clínker y $5 \%$ de yeso. Las escorias siderúrgicas son un subproducto de la fabricación del hierro y del acero y están constituidas, fundamentalmente, por silicatos alumínicos y cálcicos en estado vitreo, debido al rápido enfriamiento. Las escorias, para su empleo en la fabricación de cemen- 
tos, han de ser de características básicas - las de carácter ácido se comportan como verdaderas puzolanas- $y$ bien templadas. En realidad las escorias básicas por sí solas tienen características hidráulicas, es decir, amasedas bajo agua endurecen, si bien de una forma muy lenta. Para mejor comprenderlas se debe recurrir a la definición que de ellas hizo mi buen amigo y profesor García de Paredes: "las escorias básicas son una puzolana que tiene su propia cal"; de ahí que, al tratarlas con agua, formen compuestos puzolánicos que endurecen. El enfriamiento rápido de las mismas, es decir, su templado, las comunica una energía latente por congelación del sistema a elevadas temperaturas.

La cantidad de clínker que se adiciona a los cementos siderúrgicos no tiene más misión qúe aumentar la concentración en cal y activar su endurecimiento. Las características de estos cementos son análogas a las de los cementos puzolánicos.

\section{Durabilidad de la pasta en morteros y hormigones}

Por durabilidad de un hormigón se entiende la capacidad que posee para soportar el medio ambiente que le rodea durante aquel período de vida para el que ha sido proyectado.

Esta definición indica que un hormigón ha de ser durable en el espacio - conservar las resistencias mecánicas-y en el tiempo - vida de la obra proyectada-.

Los hormigones, como todo material de construcción, tienen enemigos y agresores y son muchos, ya que no hay que olvidar que en los procesos de ataque hay una dualidad material: las sustancias atacantes y el material resistente. Las primeras son prácticamente infinitas y el segundo $\epsilon$ s fijo puesto que es el hormigón.

$\mathrm{Si}$ analizamos las características peculiares de la pasta de cemento, éstas pueden dar una pauta para estimar su posible carácter agresivo. Las características que se van a considerar son:

- La basicidad cálcica de la pasta, y

- Su estructura porosa.

Evidentemente, si la pasta para estar estabilizada precisa de un carácter básico ( $\mathrm{pH}=$ = 13), cualquier agente externo que tenga carácter ácido o facilidad para formar compuestos cálcicos atacará a la pasta de cemento.

Un ejemplo típico de este tipo de agresión lo constituyen las aguas puras de sierra y aquéllas que llevan un elevado contenido de $\mathrm{CO}_{2}$ libre.

Las aguas puras, por carecer de sales disueltas, tienen un poder grande de disolución y, poco a poco, van disolviendo la cal de la pasta endurecida de cemento, dejando huecos en el lugar ocupado por aquélla, favoreciendo por tanto la pérdida de resistencias. Este proceso se conoce con el nombre de "lixiviación del hormigón".

Las aguas que contienen $\mathrm{CO}_{2}$ libre son muchas. $\mathrm{El}$ agua de lluvia contiene ligeras trazas de $\mathrm{CO}_{2}$, pero las zonas fabriles y las ciudades soportan un elevado contenido de $\mathrm{CO}_{2}$ atmosférico. $\mathrm{El} \mathrm{CO}_{2}$ ataca a la portlandita, formando $\mathrm{CO}_{3} \mathrm{Ca}$ y rebajando la basicidad de la pasta endurecida y por ende su estabilidad.

\section{Corrosión por formación expansiva}

Los agentes atacantes por excelencia del hormigón son los iones sulfato, $\mathrm{SO}_{4}=\mathrm{y}$ los iones magnesio, $\mathrm{Mg}^{++}$. 
Los iones sulfato atacan a la pasta endurecida de cemento por formación de ettringita con los aluminatos cálcicos. La formación de este compuesto tiene lugar con un considerable aumento de volumen, dando lugar a la rotura de los elementos de hormigón.

Como norma general debe adoptarse que la causa primaria de este ataque es la presencia de un elevado contenido de $\mathrm{AC}_{3}$ en los cementos. En consecuencia, como primera medida, en presencia de iones sulfato ha de adoptarse el empleo de cementos exentos de aluminatos, o que su contenido no supere el $5 \%$.

El ion magnesio es causa también de la formación de un compuesto disruptivo de la masa endurecida del hormigón, denominado brucita, que se forma por desplazamiento del ion calcio en la portlandita, por ion magnesio. El ion calcio es arrastrado por la disolución atacante y la pasta endurecida, aparte de perder resistencia, debilita su basicidad cálcica.

Para paliar la acción del ion magnesio se hace preciso el empleo de cementos de poca basicidad, con el fin de que la portlandita no pueda reaccionar. Se recomienda el uso de cementos puzolánicos y de escorias.

Debe obserarse que el cemento tipo P-Y ó PAS no evita el ataque del ion magnesio, ya que tiene la basicidad cálcica propia de un cemento portland.

La presencia de iones cloruro junto a los iones sulfato retrasa la acción de estos últimos. actuando en el sentido de disolver los sulfoaluminatos o ettringita.

El ataque de disoluciones que contienen sulfatos y magnesio con la presencia o no de cloruros, se contrarresta mediante el empleo de cementos PAS-PUZ o de escorias. Este es el caso de las obras en agua de mar.

\section{Corrosión de las armaduras}

La pasividad de las armaduras frente a la oxidación viene respaldada por la elevada basicidad de la pasta hidratada. Cuando la basicidad de la pasta es inferior a $\mathrm{pH}=9$, las armaduras comienzan a mostrar síntomas de corrosión por formación de hidróxido de hierro, denominado orín, su formación es exparsiva y, por lo tanto, la armadura se despega de la masa, formando grietas que favorecen el acceso de agentes externos.

Debido a la baja basicidad de los cementos puzolánicos, su uso no se recomienda en hormigones armados; pero recientemente la experiencia ha demostrado que, si la armadura está suficientemente recubierta, no sufre alteración alguna.

\section{LOS ENSAYOS DE LABORATORIO Y SU INTERPRETACION PRACTICA}

Los Pliegos de Condiciones y las Normas de distintos países recogen un conjunto de ensayos a los que generalmente se les fijan límites.

El usuario normalmente, cuando contempla los resultados de un Laboratorio de Control, no sabe interpretar las cualidades del cemento analizado.

Voy a tratar de interpretar las determinaciones más usuales de las distintas Normas. 


\section{Superficie específica}

Es un índice del grado de molturación de un cemento. Los resultados acostumbran a expresarse en $\mathrm{cm}^{2} / \mathrm{g}$.

En primer lugar hay que hacer constar que tanto el Permeabilímetro de Blaine como el Turbidímetro de Wagner, ambos aparatos para medir el parámetro que nos ocupa, no dan valores absolutos y solamente los valores lo son a efectos comparativos.

Como es lógico, cuanto mayor sea el número de $\mathrm{cm}^{2}$ que presente un gramo de cemento, tendrá:

- mayor reaccionabilidad (mayores resistencias),

- mayor can`idad de agua de amasado (a igualdad de consistencia).

Ahora bien, en una determinada zona, las resistencias aumentan, aun cuando se precise más agua de amasado; pero sobrepasado un cierto límite, el exceso de agua da lugar a fenómenos secundarios perjudiciales al usuario, tales como retracciones, microfisuraciones y falsos o anómalos fraguados en morteros y hormigones.

Las experiencias realizadas en el Bureau of Reclamation indican que la cantidad de agua requerida para conseguir una consistencia dada, aumenta en función de la finura del cemento hasta un valor de $4.000 \mathrm{~cm}^{2} / \mathrm{g}$. Entre este valor y $4.800 \mathrm{~cm}^{2} / \mathrm{g}$, el agua de consistencia permancce constante. A partir de él, el agua vuelve a aumentar con la finura.

Las finuras ideales de los cementos portland son de 3.500 a 4.600. Finuras inferiores a 3.500 indican una falta de molturación y, por consiguiente, pérdida de las características del cemento. Finuras superiores indican que las resistencias se consiguen a costa de molturación en lugar de una mejora en el clínker. Cuando las resistencias se consiguen mediante una mejora del clínker, el esfuerzo industrial es digno de aplauso, pero si únicamente se logra a costa de la finura parece censurable.

Hay que lamentar la supresión de este ensayo en el RC-75 y sobre todo no haber limitado la finura de los cementos P-450, P-550 y ARI.

\section{Ensayo de expansión en autoclave}

Este ensayo, tanto ejecutado por el método del autoclave, como por las agujas de Le Chatelier, trata de medir la estabilidad de las pastas puras de cemento.

Un concepto fundamental para poder considerar en su verdadera dimensión los fenómenos de expansión es el hecho de que la pasta de cemento goza de un período plástico, durante el cual es capaz, debido a su estructura semideformable, de absorber los esfuerzos internos originados por las diversas reacciones expansivas sin deteriorar su estructura. Este período de plasticidad comprende, de forma aproximada, desde el comienzo de fraguado hasta las 18 horas posteriores a su amasado. En muy raras ocasiones se prolonga más de 24 horas.

El ensayo de expansión, sea de la naturaleza que sea, siempre se efectúa después de las 24. horas, por lo menos, de amasada la pasta, con el fin de que la estruciura de la misma se encuentre en período de endurecimiento no plástico o anelástico.

Al cabo de estas 24 horas no todas las pastas presentan las mismas características físicas de resistencia y muy bien puede darse el caso de que si las resistencias desarrolladas son 
capaces de contrarrestar o soportar los esfuerzos expansivos originados, no se observará deformación en el supuesto de que exista una expansión.

Debido a la elevada finura de los cementos actuales, sus pastas desarrollan las resistencias con la rapidez necesaria para soportar los esfuerzos del ensayo del autoclave y, por supuesto, de las agujas de Le Chatelier.

Un cemento P-450 o un ARI es prácticamente imposible que no soporten el ensayo de estabilidad. Sin embargo, un cemento que soporta el autoclave puede que no cumpla esta prescripción, si se le agregan adiciones que debiliten sus resistencias en las primeras edades.

Los compuestos presentes en el clínker de cemento, que pueden originar expansión, son: la "cal libre" y la "magnesia libre" en estado cristalino de periclasa, los aluminatos cálcicos cristalizados por enfriamiento lento y un elevado contenido de yeso.

Mi opinión particular a este respecto, avalada por la experiencia, es que el ensayo de autoclave tal y como se efectúa en la actualidad y con límites autorizados con los Pliegos y Normas vigentes no indica gran cosa, todo lo más una falta de enfriamiento en el clínker empleado para fabricar el cemento.

El Dr. D. José Calleja ha formulado un conjunto de conclusiones que, por su importancia, me parece muy oportuno transcribir:

- El ensayo de autoclave no es totalmente seguro.

- No es representativo del carácter expansivo de los cementos.

- No se puede aplicar con igual criterio a todos los cementos.

Personalmente considero que el ensayo de autoclave debería tener los límites:

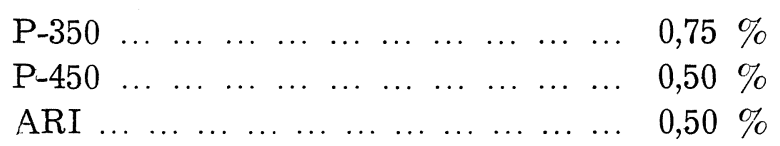

un valor que sobrepase puede indicar un sín Łoma a tener en consideración.

El actual Pliego RC-75 fija un límite de 1,00 \% para todos los cementos.

\section{Tiempo de fraguado}

El tiempo de fraguado está íntimamente relacionado con la superficie específica y su contenido de yeso.

Cuanto más elevada sea su finura antes endurece la pasta y, por consiguiente, precisa un contenido de $\mathrm{SO}_{3}$ más elevado para la regulación.

Los cementos actuales, correctamente molidos y regulados, no deben tener su principio antes de 1 hora 15 minutos y su final después de las 8 horas.

El Pliego actual indica 45 minutos y el final después de las 12 horas. 


\section{Resistencias mecánicas}

Aceptadas las condiciones de los distintos Pliegos, debe el usuario comprobar la homogeneidad de resistencias a las distintas edades, con el fin de unificar los gradientes de resistencia de los distintos elementos de hormigón puestos en obra.

A este respecto, las Comisiones Permanentes de algunos países ya están proponiendo que sería muy conveniente establecer un límite máximo para la resistencia a compresión a la edad de 3 días, para los cementos tipo portland.

\section{Pérdida al fuego}

Un valor elevado indica un mal almacenamiento, que ha dado lugar a fenómenos de carbonatación y meteorización del cemento o, lo que es peor, una adición de caliza al cemento.

Es evidente que, en condiciones normales, los cementos se meteorizan poco a poco y que no debería tolerarse una pérdida al fuego superior, por ningún motivo, al $3 \%$. Valores superiores indican o un mal almacenamiento o una adición caliza.

El Pliego tolera hasta un $4 \%$.

\section{Residuo insoluble}

Es un índice de la falta de cocción o, generalmente, una adición de tipo arcilloso.

Valores superiores a un $0,75 \%$ pueden considerarse significativos de los defectos apuntados, aun cuando el Pliego actual tolere hasta un $3 \%$.

\section{Trióxido de azufre}

Se considera como valor límite un $4 \%$ para los cementos portland normales con un contenido normal de aluminatos de calcio.

Los cementos P-450 y ARI, dada su elevada finura, toleran hasta un 4,5\%.

Valores superiores pueden considerarse anormales. 